\title{
A Single Mutation in the Hepta-Peptide Active Site of Aspergillus niger PhyA Phytase Leads to Myriad Biochemical Changes
}

\author{
Abul H. J. Ullah, Kandan Sethumadhavan, Stephanie Boone, Edward J. Mullaney \\ Southern Regional Research Center, Agricultural Research Service, United States Department of Agriculture, New Orleans, USA \\ Email: ${ }^{*}$ abul.ullah@ars.usda.gov
}

Received July 6, 2012; revised August 5, 2012; accepted August 13, 2012

\begin{abstract}
The active site motif of proteins belonging to "Histidine Acid Phosphatase" (HAP) contains a hepta-peptide region, RHGXRXP. A close comparison among fungal and yeast HAPs revealed the fourth residue of the hepta-peptide to be E instead of A, which is the case with A. niger PhyA phytase. However, another phytase, PhyB, from the same microorganism has a higher turnover number and it shows $\mathrm{E}$ in this position. We mutated A69 residue to $\mathrm{E}$ in the fungal PhyA phytase. The mutant phytase shows a myriad of new kinetic properties. The $\mathrm{pH}$ profile shifted $0.5 \mathrm{pH}$ unit in both 5.0 and 2.5 bi-hump peaks. The optimum temperature shifted down from $58^{\circ} \mathrm{C}$ to $55^{\circ} \mathrm{C}$. However, the greatest difference was observed in the mutant protein's reaction to $\mathrm{GuCl}$ at a concentration of 0.1 to $0.2 \mathrm{M}$. The activity of the mutant phytase jumped $100 \%$ while the wild type protein showed no activity enhancement in the same concentration range of $\mathrm{GuCl}$. The kinetics performed at higher concentration of $\mathrm{GuCl}$ also contrasted the difference between the wild type and mutant phytase. While $\mathrm{K}_{\mathrm{m}}$ was least affected, the $\mathrm{V}_{\max }$ increased for the mutant and decreased for the wild type. The sensitivity towards myo-inositol hexasulfate, a potent inhibitor, was decreased by the mutation. All in all, A69E mutation has affected a multitude of enzymatic properties of the protein even though the residue was thought to be non-critical for phytase's catalytic function notwithstanding its location in the conserved hepta-peptide region of the biocatalyst.
\end{abstract}

Keywords: Phytase; Histidine Acid Phosphatase; Aspergillus niger; Site-Directed Mutagenesis

\section{Introduction}

Aspergillus niger produces one of the most active phytate degrading phosphomonoesterase (E.C.3.1.3.8) that hydrolyzes myo-inositol hexa-phosphate (phytic acid) at acidic $\mathrm{pH}[1,2]$. The enzyme was overexpressed by cloning the phyA gene in the original host in early 1990s, which led to the commercialization of the enzyme [3]. The recombinant phytase was marketed under the brand name Natuphos ${ }^{\mathrm{TM}}$ to be used as a feed supplement in plant-derived poultry and swine feed to degrade phytate that are present in the soybean meal. Phytate is a known antinutrient that binds minerals; therefore, when present in high amounts, it robs the animals of divalent cations [4].

One way to circumvent this problem is to add very active phytase that could hydrolyze myo-inositol hexaphosphates in a stepwise fashion from hexa to penta to tetra phosphate and so on to yield myo-inositol monophosphate [5].

*Corresponding author.
Of all the phytases reported, two microbial phytases that had drawn the attention are PhyA phytase from Aspergillus niger and AppA2 phytase from Escherichia coli for their high catalytic efficiency [6,7]. Both of these phytases belong to the 'Histidine Acid Phosphatase' (HAP) family of the acid phosphatase, which contains a conserved hepta-peptide region in the active site with the sequence RHGXRXP $[8,9]$. The fourth amino acid in the hepta-peptide, which is represented by the letter $X$, is seen to be extremely variable [8]. Both charged amino acid such as D and $\mathrm{E}$ and amino acids with aliphatic side chain such as A, V, L, and S could occupy this position. Of particular interest to us were $\mathrm{E}$, which was the case with Aspergillus niger PhyB phytase that showed higher turnover number [10]. In Saccharomyces cerevisiae both acid phosphatase 3 (ACP3) and acid phosphatase 5 (ACP5), the sequence alignment had revealed $\mathrm{E}$ in this spot. Therefore, we opined that $\mathrm{E}$ might have a role in determining the higher catalytic turnover number in microbial phosphomonoesterase. With this view, we decided to mutate a single amino acid, viz., A to $\mathrm{E}$ to test 
out our hypothesis that a charged amino acid in this spot in place of an aliphatic amino acid, A, might induce chemical change(s) to effect higher catalytic efficiency. However, the myriad changes affected by this single mutation in the active site of Aspergillus niger PhyA phytase were not expected. In this communication, we report the biochemical characterization engendered by mutation A69E. Both the optimum $\mathrm{pH}$ and optimum temperature for activity was altered by the single mutation. Also, catalytic activity in the mutant was boosted $100 \%$ when $\mathrm{GuCl}$ concentration was raised to $0.1 \mathrm{M}$. We propose that the mutation has made the active site more flexible to allow the substrate to enter and the product to exit facilely. The fact that $\mathrm{K}_{\mathrm{m}}$ did not change while $\mathrm{V}_{\max }$ was increased in the mutant is indicative of a new chemical environment engendered by the side chain of negatively charged amino acid, glutamic acid, which replaced alanine, an amino acid with aliphatic side chain.

\section{Materials and Methods}

\subsection{Strains, Growth Media, and Conditions}

E. coli DH5 $\alpha$ cells were used for plasmid construction and were cultured at $37^{\circ} \mathrm{C}$ in Luria Broth (LB) media. Pichia pastoris strain X33 was obtained from Invitrogen (Carlsbad, CA) grown at $30^{\circ} \mathrm{C}$ as previously described [11]. The antibiotic zeocin (Invitrogen, Carlsbad, CA) was added at $100 \mu \mathrm{g} \cdot \mathrm{ml}^{-1}$ to yeast extract peptone-dextrose (YPD) media for yeast, and at $25 \mu \mathrm{g} \cdot \mathrm{mL}^{-1}$ to $\mathrm{LB}$ for $E$. coli. The wild type PhyA gene was cloned and expressed in Pichia pastoris strain X33 as described earlier [7].

\subsection{DNA Sequencing}

To confirm the mutation DNA sequencing was performed with the dye terminator cycle sequencing Quick Start Kit (Beckman Coulter, Fullerton, CA) using a CEQ 8000 Genetic analysis System (Beckman Coulter).

\subsection{Site-Directed Mutagenesis and Recombinant Protein Expression}

A PGAPZ $\alpha$ vector containing the phyA gene [12] was utilized to produce the mutant phytase. The QuickChange II Site-Directed Mutagenesis Kit (Stratagene, La Jolla, CA) used two oligonucleotide primers with the forward sequence 5'CTCTCCCGTCATGGAGAGCGGTATCCGACCGAC3' and reverse sequence 5'GTCGGTCGGATACCGCTCTCCATGACGGGAGAG'3 to generate the desired mutation employing thermocycler cycling parameters of 1 cycle $95^{\circ} \mathrm{C}(30 \mathrm{sec}),. 56^{\circ} \mathrm{C}(1$ min.), and $68^{\circ} \mathrm{C}$ (6 min.). P. pastoris $\mathrm{X} 33$ was utilized to express the mutant protein. The PGAPZ $\alpha$ vector containing the phyA gene was linearized by the restriction enzyme AVRII and transformed in Pichia cells by electroporation using an ECM 630 Electro Cell Manipulator (Centronics, Inc., BTX Instrument Division, San Diego, CA). The transformed cells were plated on YPD plus zeocin and sorbitol, then incubated at $30^{\circ} \mathrm{C}$ for 3 days. Single colony transformants were then transferred into liquid YPD plates in presence of zeocin and incubated at $30^{\circ} \mathrm{C}$ for 3 days and then assayed for phytase activity.

\subsection{Purification of Wild Type and A69E Mutant Phytase}

The phytase gene (phyA) from Aspergillus niger was cloned and overproduced in Pichia pastoris [7,13]. The cultures were centrifuged in a Sorvall SLA-1500 rotor for $30 \mathrm{~min}$ at $13,000 \mathrm{rpm}$ and $4^{\circ} \mathrm{C}$ to get the supernatant for further purification. The recombinant PhyA enzyme was purified using sequential ion-exchange column chromatographies first using MacroPrep ${ }^{\mathrm{TM}} \mathrm{S}$ column, a cation exchanger at $\mathrm{pH} 3.5$ and then MacroPrep ${ }^{\mathrm{TM}}$ DEAE column, an anion exchanger, at $\mathrm{pH}$ 7.0. The specific activity of the purified phytase was about 3000 nkat $/ \mathrm{mg}$ when assayed at $58^{\circ} \mathrm{C}$ and $\mathrm{pH} 5.0$ [14]. PhyA mutant, A69E was also purified following the same purification regimen. Briefly, the culture supernatant containing the expressed enzyme was precipitated using $45 \%$ to $90 \%$ ammonium sulfate. The enriched fraction was purified on MacroPrep $^{\text {TM }} \mathrm{S}(2.5 \times 2 \mathrm{~cm})$ at $\mathrm{pH} 3.5$ and MacroPrep ${ }^{\mathrm{TM}} \mathrm{Q}$ $(1.5 \times 2.3 \mathrm{~cm})$ column at $\mathrm{pH} 7.0$. In a final step, $1 \mathrm{~mL}$ UNOsphere $^{\text {тм }} \mathrm{S}$ column at $\mathrm{pH} 3.5$ was used to obtain the purified enzyme. The specific activity was about 2400 nkat/mg when assayed at $55^{\circ} \mathrm{C}$ and $\mathrm{pH}$ 5.5.

\subsection{Phytase Assay}

Phytase assays were carried out in $1.0 \mathrm{~mL}$ volume at optimum temperatures $\left(55^{\circ} \mathrm{C}\right.$ for $\mathrm{A} 69 \mathrm{E}$ and $58^{\circ} \mathrm{C}$ for PhyA) in $25 \mathrm{mM}$ Glycine or $25 \mathrm{mM}$ sodium acetate buffers [2]. The liberated inorganic ortho-phosphate was quantitated spectrophotometrically by following the method of Heinonen and Lahti [15] using a freshly prepared acetone-molybdate-acid (AMA) reagent consisting of 2 parts anhydrous acetone, 1 part $10 \mathrm{mM}$ ammonium molybdate, and 1 part $2.5 \mathrm{M}$ sulfuric acid. Adding $2.0 \mathrm{~mL}$ of AAM per assay tube terminated the enzyme assay. After $30 \mathrm{sec}, 100 \mu \mathrm{L}$ of citric acid $(1.0 \mathrm{M})$ was added to each tube to fix the color. Absorbance was read at $355 \mathrm{~nm}$ after blanking the spectrophotometer with the appropriate control. Phytase activity was expressed as nkat/mL (nmoles ortho-phosphate released per sec). The $\mathrm{pH}$ used for PhyA and A69E mutant were 5.0 and 5.5, respectively, during kinetic experiments, unfolding experiments, and myo-inositol hexasulfate inhibition experiments. 


\subsection{Phytase Activity at Various pH Range}

An aliquot containing the phytases were incubated in a water bath with the following buffers: $25 \mathrm{mM}$ glycine- $\mathrm{HCl}$ (pH 1.0 to 3.5 ), $50 \mathrm{mM}$ acetate (pH 4.0 to 5.5), and $50 \mathrm{mM}$ imidazole (pH 6.0 to 8.0 ), and $50 \mathrm{mM}$ Tris-maleate $(\mathrm{pH}$ 9.0). Phytase activity was measured after addition of $10 \mathrm{mM}$ phytate as described before.

\subsection{Temperature Optima}

Similar to the previous experiment, the activity measurements were conducted in a water bath from $22^{\circ} \mathrm{C}$ to $70^{\circ} \mathrm{C}$.

\subsection{Unfolding in Presence of GuCl}

Experiments were conducted in presence of 0 to $1 \mathrm{M}$ $\mathrm{GuCl}$ and phytase activity was measured during unfolding of the phytases. For $\mathrm{K}_{\mathrm{m}}$ measurements, an aliquot of the PhyA wild type (WT) and the mutant phytase were incubated with varying concentrations $(0$ to $750 \mu \mathrm{M})$ of phytate in presence of $880 \mathrm{mM} \mathrm{GuCl}$ for PhyA and 250 $\mathrm{mM} \mathrm{GuCl}$ for $\mathrm{A} 69 \mathrm{E}$.

\subsection{Myo-Inositol Hexasulfate Inhibition}

Similarly, phytases were incubated with 0 to $500 \mu \mathrm{M}$ myo-inositol hexasulfate, MIHS, and activity measurements were made. For $\mathrm{K}_{\mathrm{m}}$ determination, PhyA phytase was carried out in presence and absence of $30 \mu \mathrm{M}$ MIHS and 0 to $1000 \mu \mathrm{M}$ phytate concentration. With A69E mutant phytase, experiments were performed with 300 $\mu \mathrm{M}$ MIHS. The $\mathrm{K}_{\mathrm{i}}$ for MIHS was calculated for both the phytases.

\subsection{Stability of Phytase at $4^{\circ} \mathrm{C}$}

The $\mathrm{pH}$ of the culture supernatants after collection were adjusted to $2.5,3.5,5.2,7.2$ and 8.5 with $2 \mathrm{~N}$ sodium hydroxide or $4 \mathrm{~N}$ hydrochloric acid in $10 \mathrm{~mL}$ glass tubes with cap. The volume after adjusting the $\mathrm{pH}$ was held at $5.0 \mathrm{~mL}$ in all tubes. The tubes were kept at $4^{\circ} \mathrm{C}$ for up to 20 days. Phytase activity was measured at $0,2,7,12$, and 20 days. The activity observed before adjusting $\mathrm{pH}$ of the supernatant was taken as 100 per cent.

\section{Results}

\subsection{Effect of A69E Mutation on pH Optima}

The $\mathrm{pH}$ versus activity profile for both the WT and A69E mutant phytase are shown in Figure 1.

The usual bi-hump curve for $\mathrm{pH}$ profile, which is so characteristics for fungal PhyA phytase, was retained by the mutant phytase. However, it is not identical to the profile obtained for the WT phytase. First, the $\mathrm{pH}$ profile has become narrower in the mutant phytase as evidenced

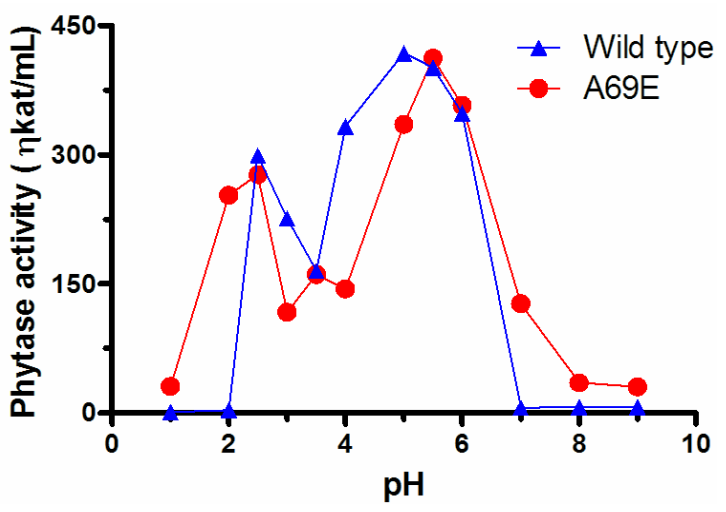

Figure 1. The pH versus activity profile of the WT and A69E mutant phytase.

by the width of the peak. Second, the mutant protein could still hydrolyze phytic acid at $\mathrm{pH} 7.0$ whereas, the WT phytase failed to catalyze the phosphomonoesterase activity at the neutral $\mathrm{pH}$. Third, the mutant phytase could hydrolyze phytase at $\mathrm{pH} 2.0$ as opposed to the WT that ceases to catalyze hydrolysis of phytate at this $\mathrm{pH}$. Fourth, the mutant phytase had an additional minor peak at $\mathrm{pH} 3.5$ and two troughs at $\mathrm{pH} 3.0$ and 4.0. Conversely, the WT phytase has one trough at $\mathrm{pH} 3.5$ (Figure 1).

\subsection{Effect of A69E Mutation on Temperature Optima}

Temperature versus activity profile of $A$. niger phytase was affected by A69E mutation. Both the WT and the mutant phytase were assayed at various temperatures starting from $20^{\circ} \mathrm{C}$ to $70^{\circ} \mathrm{C}$. The profiles are shown in Figure 2. The optimum temperature for WT phytase was found to be $58^{\circ} \mathrm{C}$; however, the mutant phytase peaked at $55^{\circ} \mathrm{C}$. At $58^{\circ} \mathrm{C}$, the mutant phytase lost about $30 \%$ activity as compared to the WT phytase. At $65^{\circ} \mathrm{C}$, the WT phytase was completely inactivated whereas the mutant phytase lost about $62 \%$ of the phytase activity. Therefore, it appears that the mutation had enabled the biocatalyst to resist thermal denaturation as compared to the WT phytase.

\subsection{Effect of A69E Mutation on Thermostability}

Table 1 describes the results of the thermal studies performed with both the WT and A69E mutant phytase. The fungal PhyA phytase performs optimally at about $55^{\circ} \mathrm{C}$ when the protein is expressed in Pichia pastoris. The WT phytase loses activity progressively when subjected to 5 minutes at $60^{\circ} \mathrm{C}, 65^{\circ} \mathrm{C}$, and $70^{\circ} \mathrm{C}$. At $70^{\circ} \mathrm{C}$, it lost about $63 \%$ activity as compared to losing about $11 \%$ at $60^{\circ} \mathrm{C}$. Conversely, the mutant did not lose any activity at $60^{\circ} \mathrm{C}$ and at the severest case of $70^{\circ} \mathrm{C}$, it lost about $57 \%$ activity. A remarkable difference in thermal stability was however exhibited at $65^{\circ} \mathrm{C}$. The WT lost 


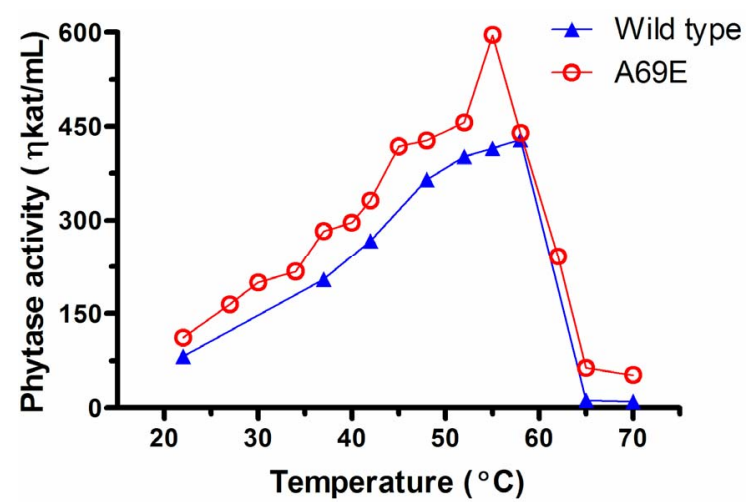

Figure 2. The temperature versus activity profile of the WT phytase at $58^{\circ} \mathrm{C}$ and $\mathrm{pH} 5.0$ and $\mathrm{A69E}$ mutant phytase at $55^{\circ} \mathrm{C}$ and $\mathrm{pH}$ 5.5.

Table 1. Thermal stability of the WT and A69E mutant phytase.

\begin{tabular}{lcccc}
\hline \multirow{2}{*}{ Phytase } & \multicolumn{4}{c}{$\begin{array}{c}\text { Phytase activity in percent after } \\
\text { exposure for 5 minute at }\end{array}$} \\
\cline { 2 - 5 } & $0{ }^{\circ} \mathrm{C}$ & $60^{\circ} \mathrm{C}$ & $65^{\circ} \mathrm{C}$ & $70^{\circ} \mathrm{C}$ \\
\hline WT & $100^{*}$ & 89 & 42 & 37 \\
A69E mutant & $100^{* *}$ & 102 & 76 & 43 \\
\hline
\end{tabular}

*542 nkat $/ \mathrm{mL} ;{ }^{* *} 437 \mathrm{nkat} / \mathrm{mL}$.

about $58 \%$ activity as compared to the A69E mutant, which lost only $24 \%$.

\subsection{Effect of A69E Mutation on Protein Unfolding in Response to $\mathrm{GuCl}$}

A differential response to increasing concentration of protein denaturant, $\mathrm{GuCl}$, was observed when both the WT and A69E mutant phytase was subjected to the unfolding reagent at the concentration rage of 0 to $1.0 \mathrm{M}$. The results are shown in Figure 3. The WT phytase behaved similarly to the results published earlier [14] when challenged with $\mathrm{GuCl}$ at its optimum $\mathrm{pH}$, viz., at $\mathrm{pH}$ 5.0. The enzyme activity was boosted $35 \%$ going from 0 to $0.55 \mathrm{M} \mathrm{GuCl}$ in a linear fashion and then the activity fell to $0 \%$ at $1.0 \mathrm{M}$ denaturant concentration. However, when A69E mutant phytase was subjected to its optimum temperature, $\mathrm{pH}$ and then challenged with increasing concentration of $\mathrm{GuCl}$, the activity had risen sharply in an exponential fashion with a final boost of $100 \%$ activity going from 0 to $0.16 \mathrm{M}$ of $\mathrm{GuCl}$ concentration. The activity then fell $12 \%$ at $0.5 \mathrm{M}$ denaturant concentration. The activity of A69E mutant phytase remained at the same level even at $1.0 \mathrm{GuCl}$. This dramatic resistance of the mutant phytase to tolerate the denaturant concentration at $1.0 \mathrm{M}$ level is the salient difference between the WT phytase and the single mutation A69E.

\subsection{Effect of A69E Mutation on Inhibition of Activity by Myo-Inositol Hexasulfate}

Myo-inositol hexasulfate (MIHS), a structural analog of phytate, is a known inhibitor of fungal phytase [16]. Both the WT and A69E mutant phytase was subjected to varying concentrations of MIHS to assess whether the single mutation has changed MIHS induced inhibition of activity vis-à-vis the WT. The results are shown in Figure 4. Even though both phytases lost total activity at $500 \mu \mathrm{M}$ concentration of MIHS, the mutant phytase showed a greater resistance to inhibition by the substrate analog. For example, while a $50 \%$ inhibition in PhyA WT phytase was achieved at $25 \mu \mathrm{M}$, for A69E mutant the same inhibition level was achieved at $375 \mu \mathrm{M}$ of the inhibitor. This was reflected in the $\mathrm{K}_{\mathrm{i}}$ of the phytases for MIHS. The mutant phytase exhibited 10 times higher $\mathrm{K}_{\mathrm{i}}$ for the substrate analog than the value obtained for the wild type phytase.

\subsection{Effect of A69E Mutation on Long Term Stability at Different pH}

Both the wild type and A69E mutant phytase was unstable at $\mathrm{pH} 8.5$ immediately after subjecting to the buffer at the start time; however, the proteins were

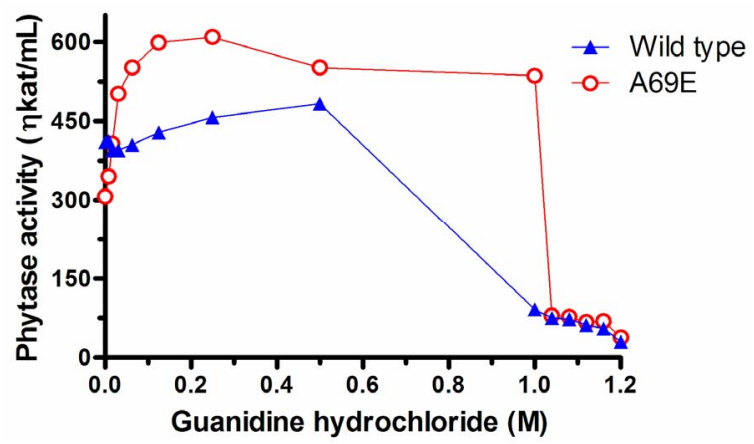

Figure 3. The effect of GuCl on the WT phytase and A69E mutant phytase.

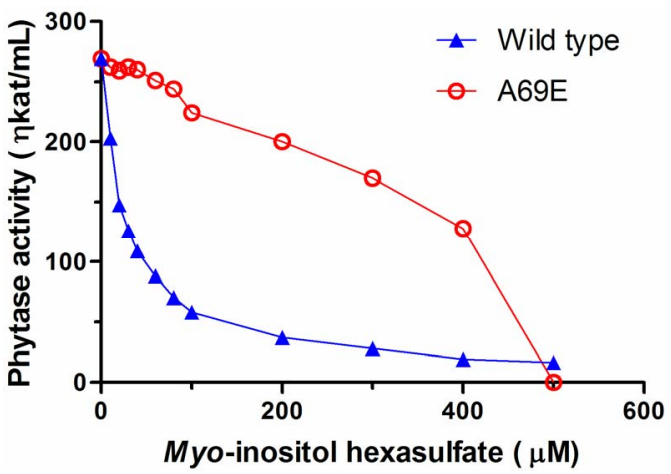

Figure 4. Inhibitory effect of myo-inositol hexasulfate (MIHS) on the activity of the WT phytase and A69E mutant phytase. 
remarkably stable at $\mathrm{pH} 7.2$ and below down to $\mathrm{pH} 2.5$ (Figure 5 panel A and panel B). For WT phytase the activity stayed the same up to 7 days and then lost $60 \%$ activity on day 12 . The activity declined further until day 20 when the experiment was terminated. The mutant phytase retained activity slightly better going from day 12 to day 20. In summary, both WT and A69E mutant phytase showed loss of activity in the $\mathrm{pH}$ range 2.5 to 7.2.

\section{Discussion}

From structural standpoint phytases belonging to HAP class of acid phosphomonoesterase have been studied exhaustively. The first reporting of any three-dimensional structure in phytase took place over a decade ago when PhyA phytase's structure was elucidated [17]. This was followed by several reporting of X-ray deduced tertiary structure elucidation in other HAP phytases [1820]. These revelations of structures set the stage for knowledge-based protein engineering via point mutations in the active center of phytases [21-23].

In this communication, we presented evidences in support of the conclusion that a single mutation in the active site of PhyA phytase had affected a host of biochemical properties such as $\mathrm{pH}$ optima, temperature optima, kinetic parameters, reaction to $\mathrm{GuCl}$ and $\mathrm{MIHS}$ (Table 2). This is very similar to the concept of "pleiotropic effect" in single gene mutation where the mutation of a gene leads to a host of phenotypic changes. In the case of A69E mutation in the fungal PhyA phytase, a single substitution of amino acid the substitution has caused a myriad of changes in both physicochemical and catalytic properties in A. niger phytase.

The original amino acid in the hepta-peptide amino acid region, where the active site resides, an A (alanine) residue is located (10). We mutated A to E (glutamic acid) to incorporate an extra negative charge in the active site of the protein which is based on the observation that PhyB phytase, which has higher turnover number than the phyA phytase, had $\mathrm{E}$ residue in the identical position [10]. The newly incorporated negative charge in the active site of phytase will have an unintended consequence vis-à-vis the accommodation of the substrate, phytate, which has six negatively charged phosphate group. The newly acquired negative charge in the active site should repel phytate as compared to the WT phytase; therefore, the $\mathrm{K}_{\mathrm{m}}$ is expected to rise in the mutant phytase. That is what is being observed in Table 1. By the same token, the $\mathrm{V}_{\max }$ should improve somewhat because the negative charge brought on by $\mathrm{E}$ into the active site should facilitate the release of negatively charged phosphate group. The turnover number increased $6.6 \%$ in the mutant phytase over the wild type phytase (Table 1). The substrate analog, MIHS, has six negatively charged sulfate groups, which should not bind as efficiently in the mutant phytases' active site as compared to the wild

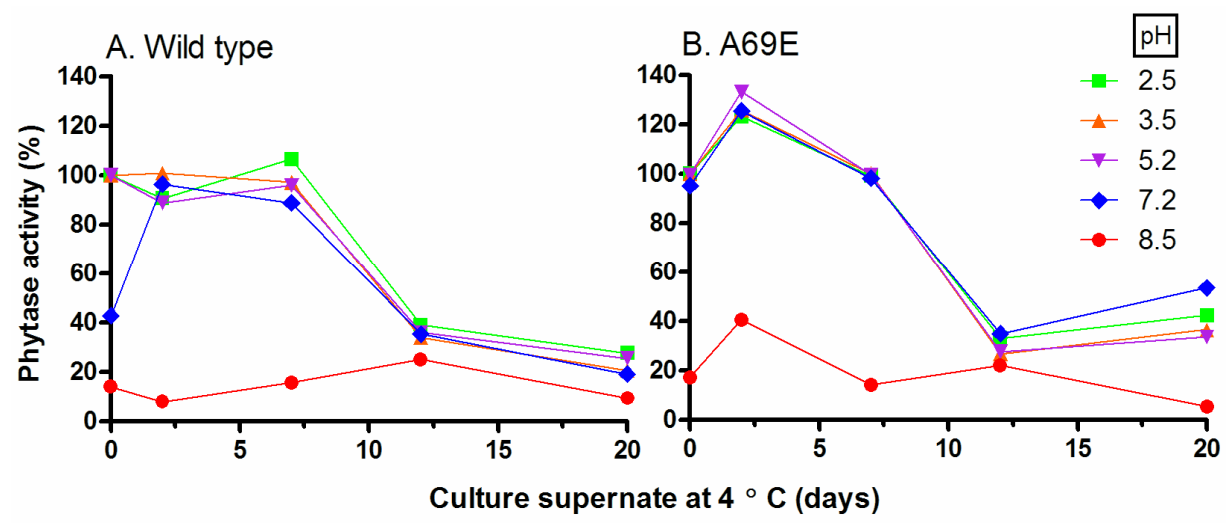

Figure 5. The long-term stability of the WT phytase (panel A) and A69E mutant phytase (panel B).

Table 2. Kinetic properties of A. niger WT and A69E phytase.

\begin{tabular}{lcc}
\hline Properties & WT phytase & A69E phytase \\
\hline $\mathrm{K}_{\mathrm{m}}(\mu \mathrm{M})$ & 50 & 170 \\
Specific activity at $\mathrm{V}_{\max }(\eta \mathrm{kat} / \mathrm{mg})$ & 1950 & 2116 \\
Turnover number $\left(\mathrm{sec}^{-1}\right)$ & 120 & 128 \\
Kinetic efficiency $\left(\mathrm{mol}^{-1} \cdot \mathrm{sec}^{-1}\right)$ & $2.3 \times 10^{6}$ & $0.74 \times 10^{6}$ \\
$\mathrm{~K}_{\mathrm{i}}$ for MIHS $(\mu \mathrm{M})$ & 8 & 83 \\
\hline
\end{tabular}


type phytase's active site. This has been confirmed by the $\mathrm{K}_{\mathrm{i}}$ values for MIHS in the mutant phytase. It took over 10 times concentration of MIHS in the mutant phytase to effect the same inhibition done by the wild type phytase. Therefore, incorporation of a negatively charged amino acid into the hepta-peptide active site region of the phytase has decreased the affinity for not only the substrate but also the inhibitor. In X-ray crystallographic studies with HAP type phytases researches have shown that sulphate groups of MIHS bind to the substrate-binding domain that is in the active center of protein $[20,24]$.

Both the $\mathrm{pH}$ optima and temperature versus activity profile had changed in the mutant phytase. The mechanism for such changes is difficult to explain due to the lack of X-ray crystallographic data; nonetheless, the charged amino acid, E, replacing the aliphatic amino acid A may allow new hydrogen bonding sites in the active site area. Also, the domain flexibility in the active center of the protein possibly brought on by the charged amino acid may explain these far-reaching effects on $\mathrm{pH}$ optima and temperature optima profiles.

The native phytases belonging to HAP family of phosphatases have already been unfolded using $\mathrm{GuCl}$ and then refolded by the removal of denaturant by dialysis $[14,25]$. However, a differential response has been observed when the WT and A69E mutant phytases were treated with varying concentrations of $\mathrm{GuCl}$. Initially, the activity was boosted $35 \%$ when $\mathrm{GuCl}$ concentration was raised to $0.55 \mathrm{M}$. We explained this phenomenon of rise in the $\mathrm{V}_{\max }$ in the light of domain flexibility brought on by $\mathrm{GuCl}$. However, in case of the mutant phytase, the activity had risen in exponential manner in response to $\mathrm{GuCl}$ at the concentration of $0.16 \mathrm{M}$. This is in sharp contrast to the WT phytase's reaction to increasing concentration of $\mathrm{GuCl}$. At higher concentration of the denaturant, when WT phytase had lost over $75 \%$ of the activity, the mutant phytase was holding onto the $100 \%$ activity gain it achieved earlier due to addition of small amounts of $\mathrm{GuCl}$. One possible reason for such discrepancy on the part of the mutant phytase could be that the altered structure containing the flexible domain was resistant to chemical denaturation.

The long-term stability of both the WT and A69E phytases in various buffers were observed; there were no discernible difference between the two phytases under the conditions. The fungal phytase was very susceptible to catalytic demise when subjected to $\mathrm{pH} 8.5$ in contrast to acidic $\mathrm{pH}$ where the proteins remain stable for days. The biochemical basis of the vulnerability of fungal phytase in alkaline $\mathrm{pH}$ is not understood at this time.

In summary, a single mutation in the hepta-peptide region that constitutes the active site resulted a myriad of both chemical and catalytic changes, which could not have been predicted. The results presented in these studies have indicated that in this class of proteins a knowledge-based approach to structural change may offer a better choice than random mutagenesis through error prone PCR technique [26,27].

\section{Conclusion}

The results of the present communication had clearly demonstrated the power of chemical probing of the active site by site-directed mutagenesis. By mutating the fourth residue $\mathrm{A}$ to $\mathrm{E}$ in the hepta-peptide active site of $A$. niger PhyA the mutant protein exhibited a myriad of new physico-chemical properties. Not only the $\mathrm{pH}$ optimum shifted $0.5 \mathrm{pH}$ unit, the temperature optimum also shifted from $58^{\circ} \mathrm{C}$ to $55^{\circ} \mathrm{C}$. Furthermore, the catalytic activity of the mutant phytase doubled as compared to the wild type phytase when subjected to 0.1 to $0.2 \mathrm{M} \mathrm{GuCl}$. A single mutation in the active site affecting so many parameters of a biocatalyst gives insight into the complexity of protein's three-dimensional structure.

\section{REFERENCES}

[1] T. R. Shieh and J. H. Ware, "Survey of Microorganisms for the Production of Extracellular Phytase," Applied Microbiology, Vol. 16, No. 9, 1968, pp. 1348-1351. http://aem.asm.org/content/16/9/1348.full.pdf

[2] A. H. J. Ullah and D. M. Gibson, "Extracellular Phytase (E.C. 3.1.3.8) from Aspergillus ficuum NRRL 3135: Purification and Characterization," Preparative Biochemistry, Vol. 17, No. 1, 1987, pp. 63-91. doi:10.1080/00327488708062477

[3] S. Haefner, A. Knietsch, E. Scholten, J. Braun, M. Lohscheidt and O. Zelder, "Biotechnological Production and Applications of Phytases," Applied Microbiology and Biotechnology, Vol. 68, No. 5, 2005, pp. 588-997. doi:10.1007/s00253-005-0005-y

[4] R. J. Wodzinski and A. H. J. Ullah, "Phytase," Advances in Applied Microbiology, Vol. 42, 1996, pp. 263-302. doi:10.1016/S0065-2164(08)70375-7

[5] A. H. J. Ullah and B. Q. Phillippy, "Immobilization of Aspergillus ficuum Phytase: Product Characterization of the Bioreactor," Preparative Biochemistry, Vol. 18, No. 4, 1988, pp. 483-489. doi:10.1080/00327488808062546

[6] A. H. J. Ullah, K. Sethumadhavan and E. J. Mullaney, "Salt Effect on the $\mathrm{pH}$ Profile and Kinetic Parameters of Microbial Phytases," Journal of Agricultural and Food Chemistry, Vol. 56, No. 9, 2008, pp. 3398-3402. doi:10.1021/jf073137i

[7] J. D. Weaver, A. H. J. Ullah, K. Sethumadhavan, E. J. Mullaney and X. G. Lei, "Impact of Assay Conditions on Activity Estimate and Kinetics Comparison of Aspergillus niger PhyA and Escherichia coli AppA2 Phytases," Journal of Agricultural and Food Chemistry, Vol. 57, No. 12, 2009, pp. 5315-5320. doi:10.1021/jf900261n

[8] A. H. J. Ullah, B. J. Cummins and H. C. Dischinger, Jr., 
"Cyclohexanedione Modification of Arginine at the Active Site of Aspergillus ficuum Phytase," Biochemical and Biophysical Research Communications, Vol. 178, No. 1, 1991, pp. 45-53. doi:10.1016/0006-291X(91)91777-A

[9] R. L. Van Etten, R. Davidson, P. E. Stevis, H. MacArthur and D. L. Moore, "Covalent Structure, Disulfide Bonding, and Identification of Reactive Surface and Active Site Residues of Human Prostatic Acid Phosphatase," Journal of Biological Chemistry, Vol. 266, No. 4, 1991, pp. 23132319.

http://www.jbc.org/content/266/4/2313.full.pdf+html

[10] A. H. J. Ullah and H. C. Dischinger, Jr., "Identification of Active Site Residues in Aspergillus ficuum Extracellular pH 2.5 Optimum Acid Phosphatase," Biochemical and Biophysical Research Communications, Vol. 192, No. 2, 1993, pp. 754-759. doi:10.1006/bbrc.1993.1478

[11] W. Zhang, E. J. Mullaney and X. G. Lei, “Adopting Selected Hydrogen Bonding and Ionic Interacttions from Aspergillum fumigatus Phytase Structure Improves the Thermostability of Aspergillus niger PhyA Phytase," Applied and Environmental Microbiology, Vol. 73, No. 9, 2007, pp. 3069-3076. doi:10.1128/AEM.02970-06

[12] T. Kim, E. J. Mullaney, J. M. Porres, R. Roneker, S. Crowe, S. Rice, T. Ko, A. H. J. Ullah, C. B. Daly, R. Welch and X. G. Lei, "Shifting the pH Profile of Aspergillus niger PhyA Phytase to Match the Stomach $\mathrm{pH}$ Enhances Its Effectiveness as an Animal Feed Additive," Applied and Environmental Microbiology, Vol. 72, No. 6, 2006, pp. 4397-4403. doi:10.1128/AEM.02612-05

[13] E. J. Mullaney, H. Locovare, K. Sethumadhavan, S. Boone, X. G. Lei and A. H. J. Ullah, "Site-Directed Mutagenesis of Disulfide Bridges in Aspergillus niger NRRL 3135 Phytase (PhyA), Their Expression in Pichia pastoris and Catalytic Characterization," Applied Microbiology and Biotechnology, Vol. 87, No. 4, 2010, pp. 1367-1372. doi:10.1007/s00253-010-2542-2

[14] A. H. J. Ullah, K. Sethumadhavan and E. J. Mullaney, "Monitoring of Unfolding and Refolding in Fungal Phytase (PhyA) by Dynamic Light Scattering," Biochemical and Biophysical Research Communications, Vol. 327, No. 4, 2005, pp. 993-998. doi:10.1016/j.bbrc.2004.12.111

[15] J. K. Heinonen and R. J. Lahti, “A New and Convenient Calorimetric Determination of Inorganic Orthophosphate and Its Application to the Assay of Inorganic Pyrophosphatase," Analytical Biochemistry, Vol. 113, No. 2, 1981, pp. 313-317. doi:10.1016/0003-2697(81)90082-8

[16] A. H. J. Ullah and K. Sethumadhavan, "Myo-Inositol Hexasulfate Is a Potent Inhibitor of Aspergillus ficuum Phytase," Biochemical and Biophysical Research Communications, Vol. 251, No. 1, 1998, pp. 260-263. doi:10.1006/bbrc.1998.9456

[17] D. Kostrewa, F. Grueninger-Leitch, A. D’Arcy, C. Broger, D. Mitchell and A. P. G. M. Van Loon, "Crystal Structure of Phytase from Aspergillus ficuum at $2.5 \AA$ Resolution," Nature Structural Biology, Vol. 4, No. 3, 1997, pp. 185190. doi:10.1038/nsb0397-185

[18] D. Kostrewa, M. Wyss, A. D'Arcy and A. P. G. M. Van Loon, "Crystal Structure of Aspergillus niger $\mathrm{pH} 2.5$ Acid Phosphatase at $2.4 \AA$ Resolution," Journal of Molecular Biology, Vol. 288, No. 5, 1999, pp. 965-974. doi:10.1006/jmbi.1999.2736

[19] D. Lim, S. Golova, C. W. Forsberg and Z. Jia," Crystal Structures of Escherichia coli Phytase and Its Complex with Phytate," Nature Structural Biology, Vol. 7, No. 2, 2000, pp. 108-113. doi:10.1038/72371

[20] K. Böhm, T. Herter, J. Müller, R. Borriss and U. Heinemann, "Crystal Structure of Klebsiella sp. ASR1 Phytase Suggests Substrate Binding to a Preformed Active Site that Meets the Requirements of a Plant Rhizosphere Enzyme," Federation of European Biochemical Societies Journal, Vol. 277, No. 5, 2000, pp. 1284-1296. doi:10.1111/j.1742-4658.2010.07559.x

[21] E. J. Mullaney, C. B. Daly, T. Kim, J. M. Porres, X. G. Lei, K. Sethumadhavan and A. H. J. Ullah, "Site-Directed Mutagenesis of Aspergillus niger NRRL 3135 Phytase at Residue 300 to Enhance Catalysis at pH 4.0," Biochemical Biophysical Research Communications, Vol. 297, No. 4, 2002, pp. 1016-1020. doi:10.1016/S0006-291X(02)02325-2

[22] Y. S. Tian, R. H. Peng, J. Xu, W. Zhao, F. Gao, X. Fu, A. S. Xiong and Q. H. Yao, "Semi-Rational Site-Directed Mutagenesis of phyils from Aspergillus niger 113 at Two Residue to Improve Its Phytase Activity," Molecular Biology Reports, Vol. 38, No. 2, 2011, pp. 977-982. doi:10.1007/s11033-010-0192-1

[23] A. J. Oakley, "The Structure of Aspergillus niger Phytase PhyA in Complex with a Phytate Mimetic," Biochemical and Biophysical Research Communications, Vol. 397, No. 4, 2010, pp. 745-749. doi:10.1016/j.bbrc.2010.06.024

[24] D. C.-C. Lim, "Bound for Catalysis. Crystal Structures of Escherichia coli Phytase and Its Complex with Phytic Acid," M.S. Thesis, Queen's University, Kingston, 1999.

[25] A. H. J. Ullah, K. Sethumadhavan and E. J. Mullaney, "Unfolding and Refolding of Aspergillus niger PhyB Phytase: Role of Disulfide Bridges," Journal of Agricultural and Food Chemistry, Vol. 56, No. 17, 2008, pp. 8179-8183. doi:10.1021/jf8013712

[26] M. S. Kim and X. G. Lei, "Enhancing Thermostability of Escherichia coli Phytase AppA2 by Error-Prone PCR," Applied Microbiology and Biotechnology, Vol. 79, No. 1, 2008, pp. 69-75. doi:10.1007/s00253-008-1412-7

[27] W. Zhu, D. Qiao, M. Huang, G. Yang, H. Xu and Y. Cao, "Modifying Thermostability of AppA from Escherichia coli," Current Microbiology, Vol. 61, No. 4, 2010, pp. $267-$ 273. doi:10.1007/s00284-010-9606-5 